Meta

Journal des traducteurs

Translators' Journal

\title{
La recepción del poeta catalán Joan Brossa en Brasil
}

\section{Ramon Farrés}

Volume 60, numéro 1, avril 2015

URI : https://id.erudit.org/iderudit/1032404ar

DOI : https://doi.org/10.7202/1032404ar

Aller au sommaire du numéro

\section{Éditeur(s)}

Les Presses de l’Université de Montréal

ISSN

0026-0452 (imprimé)

1492-1421 (numérique)

Découvrir la revue

Citer cet article

Farrés, R. (2015). La recepción del poeta catalán Joan Brossa en Brasil. Meta, 60(1), 158-172. https://doi.org/10.7202/1032404ar

\section{Résumé de l'article}

La réception du poète catalan Joan Brossa (1919-1998) au Brésil depuis les années 1990 dépasse largement le degré habituel de notoriété des auteurs catalans dans les pays d'Amérique du Sud, et même dans la plupart des pays européens. Cette situation exceptionnelle prend sa source dans l'amitié qui unissait Brossa au poète brésilien João Cabral de Melo Neto (1920-1999) au cours des années 1940, alors que Cabral occupait un poste diplomatique à Barcelone. Cependant, d'autres facteurs ont favorisé la présence de l'oeuvre de Brossa au Brésil, en dehors même de sa relation avec Cabral. Cet article cherche à retracer les voies à travers lesquelles la poésie de cet auteur est parvenue au public brésilien, à distinguer grâce à qui - poètes, traducteurs, éditeurs, artistes... - Brossa occupe actuellement une place de choix dans le système littéraire du Brésil et à fournir une liste exhaustive des oeuvres de Brossa qui y ont été publiées à ce jour.
Ce document est protégé par la loi sur le droit d'auteur. L'utilisation des services d'Érudit (y compris la reproduction) est assujettie à sa politique d'utilisation que vous pouvez consulter en ligne.

https://apropos.erudit.org/fr/usagers/politique-dutilisation/ 


\title{
La recepción del poeta catalán Joan Brossa en Brasil
}

\author{
RAMON FARRÉS \\ Universitat Autònoma de Barcelona, Barcelona, España* \\ Ramon.Farres@uab.cat
}

\begin{abstract}
RÉSUMÉ
La réception du poète catalan Joan Brossa (1919-1998) au Brésil depuis les années 1990 dépasse largement le degré habituel de notoriété des auteurs catalans dans les pays d'Amérique du Sud, et même dans la plupart des pays européens. Cette situation exceptionnelle prend sa source dans l'amitié qui unissait Brossa au poète brésilien João Cabral de Melo Neto (1920-1999) au cours des années 1940, alors que Cabral occupait un poste diplomatique à Barcelone. Cependant, d'autres facteurs ont favorisé la présence de l'œuvre de Brossa au Brésil, en dehors même de sa relation avec Cabral. Cet article cherche à retracer les voies à travers lesquelles la poésie de cet auteur est parvenue au public brésilien, à distinguer grâce à qui - poètes, traducteurs, éditeurs, artistes... Brossa occupe actuellement une place de choix dans le système littéraire du Brésil et à fournir une liste exhaustive des œuvres de Brossa qui y ont été publiées à ce jour.
\end{abstract}

\begin{abstract}
The reception of Catalan poet Joan Brossa (1919-1998) in Brazil from the 1990s to this day greatly exceeds the usual level of knowledge of Catalan authors in South American countries, and even in many European countries in most cases. This exceptional situation might be remotely justified by Brossa's friendship with Brazilian poet João Cabral de Melo Neto (1920-1999) during the 1940s, when Cabral held a diplomatic position in Barcelona. However, other factors have favoured the presence of Brossa's work in Brazil, apart from his relationship with Cabral. This article attempts to trace the different paths by which this author's poetry reached the Brazilian public, identify those responsible - poets, translators, editors, artists... - for Brossa's current high standing in Brazil's literary system and provide a comprehensive list of Brossa's works published until now in the South American country.
\end{abstract}

\section{MOTS-CLÉS/KEYWORDS}

Joan Brossa, poésie, réception au Brésil, João Cabral de Melo Neto, Ronald Polito Joan Brossa, poetry, reception in Brasil, João Cabral de Melo Neto, Ronald Polito

\section{Introducción}

La historia de la traducción, y dentro de ella el estudio de la recepción de autores y textos de una tradición literaria en otra distinta mediante la translación, ha gozado de un interés creciente entre los especialistas en las últimas décadas. Ya en 1998, Woodsworth constataba:

Interest in the history of translation has grown in recent years: conferences have focused on the subject, numerous books have appeared, and ambitious group projects have been launched. Perhaps more significant, scholars have repeatedly called for even more work to be done, emphasizing the urgency of constructing a new sub-discipline with appropriate methods and theoretical models. (Woodsworth 1998: 100) 
Desde entonces dicha tendencia no ha hecho más que confirmarse y acrecentarse, y prácticamente en cada nuevo congreso sobre traductología y en cada nueva entrega de las numerosas revistas que se ocupan de los estudios de traducción encontramos ejemplos de investigaciones sobre casos concretos de la fortuna que han tenido determinadas obras, autores individuales, escuelas literarias, etc., en sistemas culturales distintos a aquellos en que se originaron gracias al proceso de traducción y recepción. En cambio se ha avanzado menos en la elaboración de métodos o modelos teóricos que puedan servir de marco a este tipo de trabajos. Uno de los pocos estudios teóricos sobre este tema de que disponemos es el de Pym, en el que se hace la siguiente reflexión:

The central object [en los estudios sobre historia de la traducción] should be the human translator, since only humans have the kind of responsibility appropriate to social causation. Only through translators and their social entourage (clients, patrons, readers) can we try to understand why translations were produced in a particular historical time and place. To understand why translations happened, we have to look at the people involved. (Pym 1998: Ix)

A falta de un marco teórico más definido y asumido por la mayoría de historiadores de la traducción y la recepción, he decidido centrar mi estudio sobre la presencia de la obra del poeta catalán Joan Brossa en Brasil en el factor humano al que hace referencia Pym. Espero que sirva de base algún día para un estudio más general sobre la presencia de la literatura en lengua catalana en los países latinoamericanos, tal y como, en la historiografía general, la investigación de hechos a escala local o regional sirve de base para la elaboración de las grandes visiones de conjunto en los libros de historia de mayor alcance geográfico y temporal.

\section{Joan Brossa, poeta crucial en la literatura catalana del siglo $\mathrm{XX}$}

El poeta Joan Brossa (1919-1998) ocupa un lugar destacado en el canon de la poesía catalana del siglo XX, junto a Joan Maragall (1860-1911), Josep Carner (1884-1970), Carles Riba (1893-1959), Josep Vicenç Foix (1893-1987), Salvador Espriu (1913-1985), Joan Vinyoli (1914-1983) y Gabriel Ferrater (1922-1972). Algunos críticos añadirían a la lista a Joan Salvat-Papasseit (1894-1924), Pere Quart (1899-1986), Agustí Bartra (1908-1982), Josep Palau i Fabre (1917-2008), al valenciano Vicent Andrés Estellés (1924-1993) o al mallorquín Blai Bonet (1926-1997). Pero en cualquier caso existe un consenso claro en el hecho de que Brossa merece un lugar en el selecto club de los más grandes poetas catalanes contemporáneos ${ }^{1}$. Esta percepción se refleja también, como es lógico, en las traducciones: la obra de Brossa ha sido traducida a más de diez lenguas, del español al ruso, pasando por el inglés, el francés o el alemán. Si dejamos de lado las traducciones al español, que por la cercanía geográfica y política son las más abundantes -tanto en el caso de Brossa como en el de los demás autores mencionados (y prácticamente de todos los escritores que, usando el catalán como lengua literaria, han conseguido traspasar las fronteras de su ámbito cultural)-, llama la atención la relativa abundancia de obras de este poeta traducidas al portugués, y aún más el hecho de que casi todas ellas hayan sido publicadas en Brasil, un país donde la literatura catalana ha tenido históricamente una presencia apenas testimonial, aunque últimamente esto parece que esté cambiando ${ }^{2}$.

Efectivamente, el lector brasileño dispone hasta el momento de seis libros de Brossa traducidos a su lengua, mientras que en Gran Bretaña, Francia, Italia y 
Alemania -países mucho más receptivos en general a la literatura catalana- se han publicado tan solo entre uno y cuatro libros suyos, según el caso. Pero es que, además de estos seis libros publicados, los poemas de Brossa han encontrado su lugar en numerosas publicaciones especializadas de Brasil, ya sea en formato papel o electrónico, y se ha llegado a estrenar incluso un espectáculo suyo en un teatro de Río de Janeiro. Brossa, en fin, tiene una presencia sorprendentemente amplia en el mundo cultural brasileño. A ello ha contribuido, sin duda, la relación de amistad que mantuvo con João Cabral de Melo Neto (1920-1999), a su vez uno de los más grandes poetas que dio Brasil en el siglo XX. Pero, como veremos a continuación, se engañaría quien creyera que esta circunstancia biográfica basta para explicar la recepción excepcional -para un poeta en lengua catalana- que ha tenido Joan Brossa en el país sudamericano.

\section{João Cabral de Melo Neto, descubridor de Joan Brossa}

A principios de 1947, un joven diplomático de 27 años llamado João Cabral de Melo Neto llegaba a Barcelona para ocupar el cargo de vicecónsul de Brasil en la capital catalana, en lo que constituía su primera misión en el extranjero. Pero Cabral era también un prometedor poeta que en aquel momento ya había publicado sus tres primeros libros de poemas. No ha de extrañar, por lo tanto, que a los pocos meses de llegar a Barcelona adquiriera una pequeña imprenta artesanal con el objetivo de publicar sus propias obras o las de otros poetas en unas ediciones que tituló «O livro inconsútil». Fue en este sello donde dio a conocer sus dos siguientes libros de poemas, Psicologia da Composição com a Fábula de Anfion e Antiode, en el mismo año 1947, y O cão sem plumas, en 1950. Por otra parte, Cabral entró en contacto muy pronto con algunos artistas y escritores catalanes, entre los que cabe destacar a Joan Miró (1893-1983), con el que trabó amistad. Ello le permitió tener acceso al taller del pintor y escribir un ensayo sobre su obra, Joan Miró, publicado en Barcelona, pero en portugués, en 1950. También se relacionó intensamente con el grupo de artistas jóvenes agrupados en torno a la revista vanguardista Dau al Set («Dado al Siete»). Formaban parte de este grupo los pintores Antoni Tàpies (1923-2012), Modest Cuixart (1925-2007) y Joan Ponç (1927-1984), y el poeta Joan Brossa. Cabral escribió la presentación de una exposición que los tres primeros llevaron a cabo en el Instituto Francés de Barcelona a finales de 1949, así como el prólogo del libro del último Em va fer Joan Brossa, publicado en 1951, además de editar en su imprenta casera un librito de sonetos del mismo autor, bajo el título Sonets de Caruixa. En contrapartida, Brossa publicó en el número 8 de Dau al Set (datado en julio-agosto-septiembre de 1949) tres poemas del libro de Cabral $O$ engenheiro, traducidos por él mismo ${ }^{3}$. Todo ello da una idea del papel de mentor que Cabral ejerció sobre los miembros de este grupo, a pesar de que tenían más o menos su misma edad o eran solo algunos años más jóvenes. La cerrazón que vivía España en aquellos momentos, a causa de la dictadura del general Francisco Franco, hacía muy difícil que Brossa, Tàpies y compañía pudieran acceder a las ideas políticas y artísticas que circulaban por el resto de Europa y por el mundo, y Cabral, gracias a su condición de diplomático, estaba en condiciones de aportarles información y facilitarles el acceso a libros y documentos prohibidos por la censura del régimen. En este sentido, el contacto con el poeta brasileño fue importante sobre todo para introducir a aquellos jóvenes intelectuales catalanes 
en las teorías marxistas, tanto en el ámbito de la política como en el del arte y la literatura. Por su parte, Cabral conoció a través del grupo de Dau al Set una cultura perseguida y se propuso contribuir en la medida de sus posibilidades a darla a conocer fuera de España. Así nació la antología «Quinze poetas catalães» que publicó en la Revista Brasileira de Poesia, de São Paulo, en 1949, y que de hecho inauguraba la recepción de la literatura catalana en Brasil ${ }^{4}$. Sin embargo, entre los poetas traducidos por Cabral no estaba aún Brossa, seguramente porque en ese momento el joven autor no había publicado todavía ningún libro de poesía, sino únicamente poemas dispersos en revistas. En una de estas revistas, la clandestina Ariel, Cabral ya había publicado en 1948 la traducción al portugués de tres poemas de Carles Riba, que en aquel momento personificaba la resistencia cultural catalana. Una nota de presentación de Joan Triadú (1921-2010) calificaba así al traductor brasileño:

João Cabral de Melo Neto, poeta i diplomàtic brasileny que resideix aquí al servei del seu país, ha assimilat en poc temps suficients elements de la nostra cultura per donarnos amb les seves traduccions d'algunes Tannkas de Carles Riba una mostra de la seva sensibilitat exquisida i amiga. (Triadú 1948: 40)

En el mismo número de la revista se publicaba un soneto de Joan Brossa y un texto de Joan Perucho (1920-2003) sobre el pintor Joan Ponç (1927-1984), acompañado de un dibujo del artista. Además, entre los redactores de este número de Ariel se encontraban Rosa Leveroni (1910-1985), Josep Palau i Fabre (1917-2008), Josep Romeu (1917-2004) y Jordi Sarsanedas (1924-2006), todos ellos, al igual que Triadú y Perucho, presentes en la antología «Quinze poetas catalães» 5 .

En 1950 João Cabral es enviado al consulado de Brasil en Londres, y después de varios otros destinos -entre ellos Sevilla y Madrid- regresará a Barcelona en 1967 para ocupar esta vez el cargo de cónsul general, que mantendrá hasta 1972. Entre sus dos estancias en Cataluña, publica en 1956 el libro de poemas Paisagens com figuras, que incluye un retrato poético de su amigo Joan Brossa con el título de «Fábula de Joan Brossa». Esta composición poética de Cabral, y no una traducción o un artículo crítico, como suele ser lo habitual, inaugura de hecho la recepción del poeta catalán en tierras brasileñas, y lo hace en estos términos:

Joan Brossa, poeta frugal, que só come tomate e pão, que sobre papel de estiva compõe versos a carvão, nas feiras de Barcelona, Joan Brossa, poeta buscão, as sete caras do dado, as cinco patas do cão antes buscava, Joan Brossa, místico da aberração, buscava encontrar nas feiras sua poética sem-razão.

Mas porém como buscaba onde o sol és mais temporão, pelo Clot, Hospitalet, onde as vidas de artesão, por bairros onde as semanas sobram da vara do pão 
e o horário é mais comprido

que fio de tecelão,

acabou vendo, Joan Brossa,

que os verbos do catalão

tinham coisas por detrás

eram só palavras, não.

Agora os olhos, Joan Brossa

(sua trocada instalação),

voltou às coisas espessas

que a gravidez pesa ao chão

e escreveu um Dragãozinho

denso, de copa e fogão,

que combate as mercearias

com ênfase de dragão.

(Cabral de Melo Neto 1986: 334)

Esta es la primera noticia de Joan Brossa que tuvieron los lectores brasileños, con referencias, como se ve, a la típica costumbre catalana de comer el pan con tomate y al nombre -encriptado- de la revista vanguardista Dau al Set. Sin embargo, el hecho de que uno de los mayores poetas brasileños del momento -que a estas alturas ya había recibido importantes reconocimientos y había visto publicada su obra poética completa hasta la fecha- dedicara un poema a Joan Brossa no propició, como se podría haber esperado, un interés de los círculos literarios brasileños por el poeta catalán, que no lograría llevar su obra al público lector del país sudamericano hasta las postrimerías del siglo XX, aunque entonces lo hizo, como veremos, con un gran ímpetu.

Después de abandonar Barcelona definitivamente en 1972, Cabral no se reencontrará con Brossa hasta veinte años más tarde, en 1993, cuando los poetas brasileños Antonio Cícero (1945- ) y Waly Salomão (1943-2003) organizaron, en el marco de un ciclo de actividades titulado «Enciclopédia da Virada do Século», un curioso encuentro en Río de Janeiro entre tres grandes «Juanes» de la poesía internacional del fin de siglo: João Cabral de Melo Neto, Joan Brossa y el estadounidense John Ashbery (1927). Cícero y Salomão habían estado en Barcelona en 1992, participando en una mesa redonda en la Fundació Tàpies, con motivo de una exposición que se llevó a cabo allí de un artista brasileño, Hélio Oticica, y en esta circunstancia compraron el catálogo de una exposición de Brossa y supieron de la relación del poeta catalán con João Cabral a través del propio Antoni Tàpies, que ejercía de anfitrión, según ha contado el mismo Cícero (2008). Esto motivó a Cícero y Salomão a organizar unos meses más tarde el encuentro de Brossa, Cabral y Ashbery, que mantuvieron una charla en el Museu de Arte Moderna de Río. Brossa, además, realizó en esta ocasión una performance que repitió muchas veces y en muchos lugares distintos durante los últimos años de su vida. Así es como la ha descrito Cícero:

Ele havia trazido um tinteiro e uma pena de pato. Molhou a pena no tinteiro e saiu do palco, ostensivamente para escrever alguma coisa. Voltou, molhou novamente a pena e saiu. Fez isso mais uma vez, e trouxe dos bastidores um envelope fechado. Escolheu uma moça bonita na platéia -por acaso era a Renata Sorrah- entregou-lhe o envelope e lhe pediu que o abrisse dali a três minutos. Os três minutos pareceram três horas. Ao abrir a carta, estava escrito: FIM (Cícero 2008: 27). 
Brossa participó ese mismo año, como artista visual, en la XXII Bienal de Arte de São Paulo, y fue entrevistado en el suplemento cultural de la prestigiosa Folha de São Paulo (Massi 1993). Aun así, esta escapada de Brossa al Brasil para reencontrarse con su viejo amigo Cabral tampoco tuvo consecuencia alguna -por lo menos a corto plazo- desde el punto de vista de la penetración de la obra poética del autor catalán en el país sudamericano.

\section{Sérgio Alcides redescubre a Joan Brossa}

Mientras tanto, en la década de los 60 del siglo pasado, otra poeta brasileña, Stella Leonardos (1923- ), cuyo marido era de ascendencia catalana, reemprendió la tarea iniciada por João Cabral de Melo Neto de dar a conocer la poesía catalana en Brasil: entre 1965 y 1969 publicó un libro de poemas de Agustí Bartra, Mársias \& Adila, una antología de la obra poética de Félix Cucurull (1919-1996), con el título Poemas escolhidos, y una Antologia de poesia catalã contemporãnea que incluía una nómina de 50 autores, pero en la que tampoco aparecía Joan Brossa. Aún, en 1971, Leonardos publicó un Cancionário catalão en el que combinaba creaciones propias con fragmentos de poemas medievales catalanes traducidos por ella. Estos cuatro libros se publicaron en la editorial Monfort de São Paulo, propiedad de un catalán afincado en Brasil. Ya en la década de los 90, Leonardos dará a conocer a otros dos poetas catalanes: Joan Alavedra (1896-1981), con Poema do Presépio, y Francesc Faus (1931- ), con A Roda e o Vento. En estos dos últimos casos, el sello responsable de la edición fue el también paulista Giordano, que se ha distinguido en las últimas décadas por su atención a la literatura catalana, especialmente la clásica medieval, con una edición magnífica de la novela de caballerías Tirant lo Blanc, de Joanot Martorell, y de varias obras del polifacético Ramon Llull.

El hecho de que Joan Brossa no apareciera aún en la antología de Leonardos no debe extrañarnos en demasía, ya que por motivos tanto políticos -su obra tuvo dificultades recurrentes con la censura franquista- como estrictamente literarios -a pesar de su carga crítica, el carácter eminentemente vanguardista de la poesía de Brossa no encajaba con los postulados del realismo social que predominaban en los años 60 en Cataluña- nuestro autor no gozó de un reconocimiento general en el propio ámbito cultural catalán hasta la publicación de los volúmenes recopilatorios Poesia rasa (1943-59) y Poemes de seny i cabell (1957-63), publicados ya en la década de los 70, el segundo después de la muerte del dictador en 1975. Es solo a partir de este momento que Brossa adquiere el relieve público que merecía en Cataluña, como el gran poeta que era, y a consecuencia de ello empieza también a ser tenido en cuenta en las antologías de poesía catalana que se publican en otras lenguas.

Sin embargo, habrá que esperar todavía hasta finales de la década de los 90 para ver por fin a Joan Brossa traducido en Brasil: a lo largo de 1997 y 1998 los poetas Sérgio Alcides (1967- ) y Ronald Polito (1961- ) publican versiones de poemas de Brossa -la mayoría pertenecientes al libro Poemes civils, publicado por primera vez, aunque con recortes de la censura, en 1961- en varias revistas literarias de distintos puntos del país: Suplemento Literário de Minas Gerais, de Belo Horizonte (marzo de 1997); Inimigo Rumor, de Río de Janeiro (mayo-agosto de 1997); Magma, de São Paulo (noviembre de 1997), y O Percevejo, de Río de Janeiro (1998). Y aún en 1998 aparece su traducción completa de Poemas civis en la editorial Sette Letras de Río, con un 
epílogo de los dos traductores que es una magnífica carta de presentación ante el público brasileño de la personalidad y la obra de Brossa. Tanto Alcides como Polito se habían estrenado como poetas en la misma editorial dos años antes, y uno podría pensar que su interés por Joan Brossa debía de habérseles despertado a través de João Cabral de Melo Neto, aunque ambos nacieron ya con posterioridad a la publicación de la «Fábula de Joan Brossa» del poeta de Recife. Sin embargo no fue así, como sabemos por boca del propio Sérgio Alcides, que lo ha explicado en una entrevista:

Só conheci a poesia de Brossa anos depois. Foi uma das minhas maiores emoções como leitor de poesia. A descoberta aconteceu num dia memorável, na Casa de España, no Rio. Estava perdido entre as estantes da biblioteca, muito mal-organizada e simplesmente não-catalogada, naquela época. Eu queria ver o que tinha lá. Encontrei uma edição bilíngue de «Poemas civis», lombada preta, preta e larga, atraente para o olhar. Puxei. Abri o livro ao acaso: «Plou, puc» - e fui conquistado imediatamente. Na página par, a tradução castelhana me esclarecia: «Chove, posso etc.» Isso aconteceu há mais de dez anos. Eu nunca tinha ouvido falar em Brossa (provavelmente tinha lido e me esquecido do poema de Cabral em homenagem a ele $)^{6}$. Separei o livro para levá-lo emprestado. Instantes depois, encontrei uma revista de poesia, «La rosa cúbica», em número especial de homenagem ao poeta. Essas coincidências... Havia uma longa entrevista com ele, além de fotos mostrando a pessoa encantadora que ele era. $\mathrm{Na}$ entrevista ele falava também da sua amizade com Cabral, da importância que o Cabral teve para ele e para a sua geração, num período sombrio da história da Catalunha. Naquela época, eu tinha acabado de conhecer o Ronald [Polito] (publicamos poemas no mesmo número da extinta revista «Ímã»). Eu estava em Ouro Preto, uma cidade à qual sou (ou fui) muito ligado. Conheci o Ronald na inesquecível livraria Spix \& Martius, numa linda noite [...]. Uns dias depois, em Mariana, mostrei o livro de Brossa ao Ronald. Começamos a traduzir logo. Acabamos aprendendo o catalão só para isso. É uma língua linda, e não foi muito difícil. Cinco anos depois, o livro ficou pronto. Pena que o Brossa morreu bem no dia em que enviamos para ele seu exemplar. (Fernandes 2005: 12)

Este día fatídico fue el 30 de septiembre de 1998. Joan Brossa tenía 79 años y no llegó por lo tanto a ver su primer libro de poemas publicado en Brasil. Hay que suponer que sí le llegaron los avances del libro publicados en revistas y suplementos, pero difícilmente el poeta pudo siquiera intuir la amplitud de su recepción póstuma en Brasil.

En su epílogo a Poemas civis, Polito y Alcides hacían la siguiente reflexión:

É para nós imprevisível o efeito que a publicação de um livro inteiro de Joan Brossa pode ter no reduzido meio poético do país. Entretanto, temos algumas expectativas. Supomos que o despojamento formal, a cortante ironia e a lucidez acerca da dimensão política da poesia irritarão os grupos mais conservadores, seja em poética ou em política. Os Poemas civis cairão como uma bomba, a nosso ver, principalmente entre aqueles que persistem na poesia politicamente participante mas esteticamente ingênua, no lirismo confessional ou na esterilidade do formalismo. Também deverá causar estranheza o vanguardismo de Brossa, nada teleológico e muito mais aberto do que qualquer programa de nossas vanguardas literárias dos anos 50 para cá. Neste final do século XX, a extensa e variada obra de Brossa cada vez mais se impõe como uma das pouquíssimas que melhor resolveram os impasses legados pelas mais diversas vanguardas desde o romantismo até hoje. (Alcides y Polito 1998: 283)

Visto con la perspectiva del tiempo, hay que decir que, afortunadamente, Polito y Alcides se equivocaron en este pronóstico tan pesimista con respecto a la recepción 
que Brossa iba a tener en Brasil. Sólo unos meses después de la publicación de Poemas civis -y de la muerte de Brossa-, en febrero de 1999 la prestigiosa revista de São Paulo Cult publicó un extenso «Dossié Joan Brossa, 1919-1998», coordinado por el poeta y músico João Bandeira, que contenía poemas escritos, poemas visuales, poemas-objeto y un texto sobre Joan Miró de Brossa -en traducciones del propio João Bandeira, Noemi Jaffe, Sérgio Alcides y Ronald Polito-, dos entrevistas, ensayos y textos de homenaje al poeta catalán redactados, entre otros, por João Cabral de Melo Neto, Waly Salomão, Andrés Sánchez Robayna y Haroldo de Campos (1929-2003), uno de los máximos representantes de la llamada poesía concreta brasileña, que tantos puntos en común tiene con la obra de Brossa. Además se reproducía la «Fábula de Joan Brossa» de Cabral y se aportaba una bibliografía sucinta de la obra del homenajeado 7 . Unos meses más tarde el mismo Bandeira publicaría en la revista Novos Estudos un ensayo sobre el poeta catalán titulado «Joan Brossa, escova e agua de chuva» ( $n^{\circ} 55$, noviembre de 1999) ${ }^{8}$.

Estas publicaciones a caballo entre 1998 y 1999, coincidiendo con la muerte del poeta, abrieron, ahora sí, las puertas del mundo cultural brasileño a Joan Brossa. Aunque pueda parecer anecdótico, creo que es sintomático de esta súbita y amplia acogida de Brossa el hecho de que el libreto del disco que Adriana Calcanhotto -una de las nuevas voces de la música popular brasileña con más empuje en aquellos momentos- publicó en el año 2000, Público, reproduzca uno de los poemas de Brossa publicados en el dossier de Cult, en traducción de João Bandeira. En agosto del mismo año, el Suplemento Literário de Minas Gerais reproduce dos poemas visuales de nuestro autor, y al año siguiente, en 2001, se estrena en Río de Janeiro un espectáculo a partir de textos suyos para la escena, con el título Strip-tease e teatro irregular, dirigido por Daniel Dantas e interpretado por Cristina Amadeu; la traducción al portugués fue a cargo de Edla van Steen y Sylvia Wachsner. No solo los ámbitos literarios del Brasil, por lo tanto, se hacen eco de la obra de Joan Brossa en el cambio de siglo, sino también los musicales y los teatrales.

\section{Ronald Polito, embajador de Brossa en Brasil}

Pero el verdadero embajador de Joan Brossa en Brasil a partir del nuevo siglo ha sido Ronald Polito. Después de su trabajo conjunto con Sérgio Alcides en la traducción de Poemas civis, este poeta, traductor y editor siguió profundizando en la obra del autor catalán y en 2002 ofreció nuevas muestras de sus creaciones en las revistas literarias Cacto y Zine Qua Non, ambas de São Paulo. Cuatro años más tarde Polito publica su traducción de Sumário austral e outros poemas, en una edición a cargo de Vanderley Mendonça y Glòria Bordons, una de las máximas especialistas en Cataluña en la obra de Brossa, que incluía también la versión original catalana del libro -publicado por primera vez en 1999, después de la muerte del autor- y una traducción al castellano de Pere Galceran-Uyà. De la publicación trilingüe se encargó la editorial paulista Amauta.

En 2008 Ronald Polito publicó en la revista Centopeia otros ocho poemas de Joan Brossa, cuatro del libro Passat festes (1995) y cuatro de La clau a la boca (1997). En 2009 añade a su cuenta tres poemas más de Brossa en la revista digital Sibila, y otra publicación digital, Sopro, presenta una selección de creaciones del poeta catalán traducidas por Ronald Polito, Sérgio Alcides y Victor da Rosa (las traducciones 
firmadas conjuntamente por Polito y Alcides proceden del libro Poemas civis, pero encontramos también traducciones inéditas de Polito y da Rosa). En este mismo año Polito publica otro volumen de traducciones de Brossa con el título 99 poemas en otra editorial de São Paulo, Anna Blume. En este caso se trata de un libro antológico, con una selección de textos de las distintas etapas creativas del poeta catalán llevada a cabo por el propio traductor en colaboración con Victor da Rosa, quien firma además el prefacio. Pero es el mismo Polito el que aporta un extenso e interesante epílogo en que plantea toda una teoría de la creación poética brossiana a partir del concepto de «correspondencias». En 2010 aparecen otros doce poemas de Brossa traducidos por Ronald Polito en la revista digital Zunái. Y en 2011 Polito y da Rosa vuelven a colaborar en la publicación del último libro de Brossa editado hasta ahora en Brasil, Escutem esse silencio (São Paulo, Lumme Editor), un volumen recopilatorio de poemas breves con traducciones del primero y prólogo compartido.

Ronald Polito se ha convertido además, a raíz de su dedicación a Joan Brossa, en el traductor de literatura catalana de referencia en Brasil: hasta el momento ha traducido ya a una docena larga de otros autores, la mayoría poetas, entre los que encontramos algunos de los nombres claves de la poesía catalana del siglo XX citados al inicio de este artículo, como Maragall, Foix, Salvat-Papasseit y Espriu, además de una buena representación de los mejores poetas nacidos ya a mediados del pasado siglo, como Narcís Comadira (1942- ), Carles Camps-Mundó (1948- ) y MariaMercè Marçal (1952-1998), a los que hay que añadir aún algunos autores todavía más recientes incluidos en la antología 12 poetas catalães, firmada en colaboración con el poeta y traductor catalán Josep Domènech Ponsatí. Si a eso añadimos las traducciones que Polito ha realizado de narradores de la talla de Mercè Rodoreda (1908-1983), Maria Àngels Anglada (1930-1999) y Quim Monzó (1952- ), entre otros, e incluso de una obra del gran filósofo, teólogo y poeta medieval Ramon Llull (en este caso también en colaboración con Sérgio Alcides), tendremos una visión bastante clara de la enorme tarea de divulgación de la literatura catalana que este traductor incansable ha llevado a cabo durante los últimos veinticinco años en Brasil, y que no tiene precedentes ni en este país sudamericano ni apenas en ningún otro.

Justo es, sin embargo, hacer notar que Polito no está solo en esta tarea de dar a conocer la literatura catalana en Brasil. Como ya se ha mencionado, las traducciones de poetas, narradores y ensayistas catalanes realizadas en tierras brasileñas se han multiplicado en los últimos años, y si nos centramos en el ámbito de la poesía hay que destacar la muy valiosa antología elaborada por el joven poeta Fábio Aristimunho Vargas (1977- ), bajo el título Poesia catalã. Das origens á Guerra Civil, que forma parte de un magno e insólito proyecto que presenta la poesía española escrita en las cuatro lenguas oficiales (castellano, catalán, gallego y vasco) en cuatro volúmenes, publicados por la Editora Hedra de São Paulo en 2009; así como otra antología más restringida, 4 poetas da Catalunha: Joan Maragall, Carles Riba, Joan Oliver (Pere Quart), Salvador Espriu, elaborada por Luis Soler (1920- ), un músico y poeta de origen catalán afincado en Brasil, que publicó en 2010 la editora de la Universidade Federal de Santa Catarina, en Florianópolis. 


\section{Otros intérpretes brasileños de Brossa}

Tampoco la presencia de Joan Brossa en Brasil en lo que llevamos de siglo XXI se debe únicamente a la meritoria tarea de Ronald Polito y sus esporádicos colaboradores Sérgio Alcides y Victor da Rosa. Entre la publicación de Poemas civis y Sumário astral e outros poemas, las editoriales Amauta y Ateliê apostaron conjuntamente en 2005 por un volumen antológico del poeta catalán con el título Poesia vista, que tenía la particularidad de ofrecer una visión muy variada de la obra brossiana, ya que incluía tanto poemas escritos como visuales e incluso la reproducción de poemas tridimensionales, es decir poemas-objeto, todo ello organizado en tres bloques: «A letra - poemas visuais», "A palavra - poemas escritos» $\mathrm{y}$ «A forma - poemas objeto». La selección y la traducción corrieron a cargo de Vanderley Mendonça, quien como vimos colaboró también en la edición de Sumário astral e outros poemas -y que además es autor del diseño de la cubierta de 99 poemas-, y los textos introductorios los firmaron los ya también citados Glòria Bordons y Haroldo de Campos.

Dicha publicación coincidió con la llegada a São Paulo, en octubre y noviembre de 2005, de la exposición Joan Brossa: desde Barcelona ao Novo Mundo, organizada conjuntamente por el Institut Ramon Llull -el equivalente del Instituto Cervantes para la cultura catalana- y la Fundació Joan Brossa -creada en Barcelona después de la muerte del poeta- y comisariada por Glòria Bordons y Sergio González Valenzuela. La muestra incluía un centenar de obras, entre poemas visuales, objetos, instalaciones, carteles, libros y revistas, distribuidas en cuatro apartados: "Os encontros impossíveis», "A cotidianidade e o compromisso político», "O olhar essencial» $\mathrm{y}$ "A reflexão íntima», y estuvo acompañada de un programa de actos relacionados con el poeta catalán, entre los que cabe destacar un espectáculo titulado Brossa. Bros. BR que se representó en el Teatro da Universidade de São Paulo (TUSP) y en el que participaron Adriana Calcanhotto, Arnaldo Antunes, Lenora de Barros, Antonio Cícero, João Bandeira y Tom Zé, entre otros, quienes leyeron poemas de Brossa o llevaron a cabo performances en torno a su obra. Y de esta manera encontramos nuevamente el mundo literario, el musical y el escénico reunidos en Brasil alrededor de la figura de Brossa.

La exposición, que anteriormente se había visto en Santiago de Chile, viajó ya en 2006 a Porto Alegre y Río de Janeiro, antes de recalar en Argentina (Rosario y Buenos Aires) y Lisboa. En Río se publicó la versión portuguesa del catálogo de la exposición, que reproducía el prólogo que João Cabral de Melo Neto escribió para el libro Em dic Joan Brossa, una carta del poeta brasileño a su amigo catalán, un poema de Cabral traducido por Brossa, varios poemas de Brossa traducidos por Sérgio Alcides, así como textos de João Bandeira y otros especialistas en la obra de Brossa. Algunos años después se han vuelto a exponer en Brasil obras de Brossa -junto a las de otros escritores experimentales españoles e hispanoamericanos del siglo XX, hasta un total de treinta- en la muestra Escrituras en Libertad, comisariada por José Antonio Sarmiento, que, después de haberse inaugurado en Madrid en 2009, viajó por varias ciudades brasileñas: São Paulo, Río de Janeiro, Brasilia y Belo Horizonte.

Otros intérpretes y divulgadores de Joan Brossa en Brasil han sido:

- el artista y crítico Marcelo Terça-Nada, que en 2003 publicó en la Revista Etcetera, de carácter digital, un texto titulado «Joan Brossa: pequeno panorama sobre sua vida e obra», ilustrado con once poemas visuales, poemas-objeto e instalaciones del autor catalán; 
- el poeta Andityas Soares de Moura (1979- ), que en 2005 publicó tres poemas de nuestro autor en el Suplemento Literário de Minas Gerais, con una nota en la que califica a Brossa no solo como «o mais importante poeta catalão da contemporaneidade», sino también como «um dos mais creativos artistas da vanguardia europea» «ao lado de Apollinaire, Tzara, Duchamp, Breton, Artaud e Miró»;

- el poeta y cineasta Adalberto Muller, quien tradujo cuatro poemas del libro Passat festes para la revista electrónica Zunái, también en 2005;

- el artista André Vallias, que realizó una «videoversión» de la «Oda a Marx» de Joan Brossa (con música de los compositores Hans Eisler y Noel Rosa) para la revista digital Erratica, igualmente en 2005;

- el poeta Salomão Sousa (1952- ), que publicó la traducción de siete poemas de Brossa en el portal de «Poesía Ibero-Americana» que gestiona el también poeta y artista Antonio Miranda (1940- ), en febrero de 2008;

- el ya repetidamente citado Antonio Cícero, uno de los responsables de la única visita de Joan Brossa a Brasil, quien publicó en su blog personal una traducción de las dos primeras estrofas del poema «Set d'acció», en 2008, y la versión completa del poema «M'estava ajaçat», en 2010;

- el poeta Adriandos Delima (1970) -pseudónimo de Adriano Lima-, que publicó un total de seis poemas de Brossa traducidos por él mismo -además de un poema propio en homenaje al poeta catalán- en su blog «Rima\&via Poesia Nova», entre noviembre de 2010 y enero de 2011;

- los poetas Angélica Freitas (1973- ), Marília Garcia (1979- ) y Ricardo Domeneck (1977- ) -este último descendiente de catalanes-, quienes en 2011 publicaron en la revista digital que editan, Modo de Usar \& Co., un vídeo de la famosa performance de Brossa ya citada antes, «Fi», grabado en Barcelona un año antes de la muerte del «gran poeta experimental catalão», como lo definen ellos.

Además de todo lo dicho, durante los últimos años los poemas de Joan Brossa - ya sean escritos o visuales - se han reproducido en multitud de blogs de aficionados a la literatura brasileños, y en las universidades del país han empezado a escribirse trabajos de investigación, tesinas o tesis dedicadas al poeta catalán. En São Paulo existe ya incluso una "Rua Joan Brossa".

Parece confirmarse, por lo tanto, lo que escribió ya en 2005 Haroldo de Campos, en su prefacio a Poesia vista:

Hoje, depois da cuidada tradução dos Poemas civis por Ronald Polito e Sérgio Alcides (1999), e do trabalho ensaístico e tradutório do jovem poeta visual João Bandeira [...], pode-se dizer que o autor da «Sextina Cibernética» [uno de los poemas más célebres de Brossa] entrou na circulação sangüínea da mais nova poesia brasileira. (Campos 2005: 15)

Y todo hace presagiar que la presencia de Joan Brossa en Brasil va a seguir creciendo y profundizándose en el futuro próximo.

\section{Conclusiones}

Joan Brossa es uno de los grandes poetas catalanes del siglo XX, y como tal ha sido traducido a las principales lenguas de cultura, a pesar de las dificultades inherentes a los escritores que se expresan en lenguas minorizadas para trascender su propio espacio cultural. Su recepción destacada en el ámbito cultural brasileño parecería justificarse a primera vista por la estrecha relación que mantuvo con el poeta João Cabral de Melo Neto, quien ocupó un cargo diplomático en Barcelona a finales de 
los años 40 del siglo XX, justo cuando Brossa iniciaba su andadura literaria. Sin embargo, el estudio de la progresiva llegada de las obras del poeta catalán a Brasil, que no arranca hasta mucho más tarde, demuestra que fueron otros factores y otros actores los que propiciaron esta recepción inusitada de un creador en lengua catalana en un país como Brasil, con una tradición muy pobre en este terreno. Entre estos actores ocupa un lugar destacadísimo el poeta, editor y traductor Ronald Polito, quien ha dado a conocer a Joan Brossa con versiones de sus poemas en un gran número de revistas literarias brasileñas y posteriormente con la publicación de varios volúmenes -de carácter unitario o antológico- dedicados a su obra. A partir del trabajo intensivo de Polito desde los años 90 del siglo pasado, las creaciones de Brossa -que abarcan no solo la poesía en sentido estricto, sino también la poesía visual, los poemas-objeto, las instalaciones y las performances- parecen haber calado en el imaginario cultural de Brasil, y en lo que llevamos de siglo XXI son muchos los poetas, artistas, críticos y académicos de este gran país que han dialogado con la obra del autor catalán mediante nuevas traducciones, adaptaciones, recreaciones, comentarios, etc., tanto en el ámbito de la edición tradicional, en libros o publicaciones periódicas, como en el de los nuevos medios electrónicos, donde los poemas y las obras plásticas de Joan Brossa circulan con una libertad que sin duda habría complacido a este defensor de la palabra emancipada y sin fronteras.

\section{NOTAS}

* Este artículo se inscribe en el Grup d'Estudi de la Traducció Catalana Contemporània (GETCC), 2009, SGR 1294, reconocido y financiado por la Agència de Gestió i Ajuts Universitaris de la Generalitat de Catalunya, y en el proyecto «La traducción en el sistema literario catalán: exilio, género e ideología (1939-2000)» (FF12010-19851-C02-01), financiado por el Ministerio Español de Ciencia e Innovación.

1. Junto a sus más de 70 libros de poemas, Joan Brossa escribió también piezas teatrales e incluso, como veremos, se dio a conocer como artista plástico con obra gráfica y escultórica; pero él mismo denominaba «poesía escénica» a su teatro y «poemas visuales» o «poemas-objeto» a sus incursiones en el terreno de las artes plásticas. La denominación global de poeta está por lo tanto más que justificada.

2. No encontramos autores catalanes publicados en Brasil hasta finales de la década de los 40 del siglo XX, y su presencia es muy esporádica hasta finales de la década de los 80 . En la década de los 90 ya se observa un aumento considerable de traducciones del catalán en el país sudamericano, y en lo que llevamos de siglo XXI el público brasileño ha tenido acceso a una cincuentena de libros de autores catalanes, más de los que se publicaron en todo el siglo anterior.

3. Se trata de «As nuvens», «A paisagem zero» $\mathrm{y}$ «A bailarina», los tres primeros poemas del libro, por este orden, aunque en la versión publicada por Joan Brossa «A bailarina» precede a los otros dos.

4. Sobre las implicaciones de esta antología en la obra poética propia de João Cabral de Melo Neto, se puede consultar el artículo de Souza de Carvalho (2009).

5. Cabral no se limitó a traducir del catalán las tres tankas de Carles Riba y los quince poemas de la antología "Quinze poetas catalães», tal como explicó él mismo muchos años después, en 1988, a raíz de una entrevista radiofónica: «Aqueles poemas que saíram na Revista Brasileira de Poesia são de poetas catalães de minha geração e foram traduzidos da primeira vez em que estive lá. Em 1954 houve o Centenário de São Paulo, e uma sociedade catalã abriu um concurso para poemas traduzidos do catalão e Domingos Carvalho da Silva me convidou para participar. Aqueles 17 poemas já não eram inéditos e eram poucos para participar de um concurso assim, de forma que eu acabei outras traduções dos poetas que eu tinha começado na Catalunha e de poetas mais antigos que esses da minha geração. Há gente interessada em publicar isso, mas acontece que eu cheguei de Portugal e ainda não arrumei todo o meu arquivo e todos os meus livros. É uma coisa de tanto tempo, de 54 para cá, que eu quero reler para ver se vale a pena publicar» (Ferreira y Vasconcellos 
1990. La entrevista se puede leer también en la revista digital Tiro de Letra. Mistérios da Criaçao Literária 2007 (http://www.tirodeletra.com.br/entrevistas/JoaoCabraldeMeloNeto.htm). No sabemos si estas traducciones se han conservado en los archivos de Cabral, pero en cualquier caso han permanecido inéditas hasta hoy.

6. Quizás para enmendar ese olvido, la edición brasileña de Poemas civis reproduce en la contracubierta el poema de Cabral.

7. La portada de la revista reproducía una foto de Brossa jugando con una baraja de cartas, y titulaba: «Joan Brossa, o mago da poesia visual».

8. João Bandeira explicaría años más tarde que supo de la existencia de Joan Brossa por el encuentro de Río de 1993 con João Cabral de Melo Neto y John Ashbery, y que cinco años más tarde visitó al poeta catalán en Barcelona junto con Noemi Jaffe para hacerle una entrevista. Dicha entrevista, titulada "Entre o semántico e o visual," fue uno de los documentos recogidos en el dossier de la revista Cult (Bandeira y Jaffe 2012).

\section{REFERENCIAS}

Alcides, Sérgio y Polito, Ronald (1998): Posfácio. A harpa viva: natureza, civilidade e poesia em Joan Brossa. In: Joan Brossa. Poemas civis. Río de Janeiro: Sette Letras, 261-283.

Bandeira, João y Jaffe, Noemi (2012): Brossa e os palhaços. Barcelona, junho de 1998. Conteúdo livre (abril de 2012). Consultado el 4 de agosto de 2012, <http://sergyovitro.blogspot.com. br/2012/04/brossa-e-os-palhacos-noemi-jaffe-joao.html $>$.

Cabral de Melo Neto, Joan [sic] (1949): La ballarina, Els núvols. Paisatge zero. (Traducido al catalán por Joan BrossA) Dau al Set. 8(julio-agosto-septiembre de 1948):9-12. Consultado el 5 de abril de 2013, <http://mdc2.cbuc.cat/cdm/compoundobject/collection/dauset/id/75/ $\mathrm{rec} / 8>$.

Cabral de Melo Neto, João (1949): Quinze poetas catalães. Revista Brasileira de Poesia. IV(febrero):29-43. (Recientemente estas traducciones de Cabral se han reeditado en (N. T.) Revista Literária em Tradução. 1(septiembre de 2010):237-267. Consultado el 19 de marzo de 2013, <http://en.calameo.com/read/00026024543d2f9c28b01>.

Cabral de Melo Neto, João (1986): Poesia completa 1940-1980. Rio de Janeiro: Imprensa Nacional- Casa da Moeda.

Cícero, Antonio (2008): Meu contato com Joan Brossa. Diario Catarinense 8 de marzo de 2008. Consultado el 27 de marzo de 2013, <http://antoniocicero.blogspot.com.br/2008/03/meucontato-com-joan-brossa.html>.

DE CAmpos, Haroldo (2005): Joan Brossa e a poesia concreta. In: Joan Brossa. Poesia vista. São Paulo: Amauta Editorial y Ateliê Editorial, 11-15.

Fernandes, Pádua (2005): Poesia e política: entrevista com Sérgio Alcides. Jandira. 2(octubre de 2005):10-15. Consultado el 1 de abril de 2013, <http://opalcoeomundo.blogspot.com. br/2010/10/poesia-e-politica-entrevista-com-sergio.html $>$.

Ferreira, Claudiney y VAsconcellos, Jorge, eds. (1990): Certas Palavras. São Paulo: Estação Liberdade: Secretaria de Estado da Cultura.

MAssi, Augusto (1993): Entrevista: Brossa fala da lição de Cabral. Folha de São Paulo, "Mais!," 24 de octubre de 1993.

Pym, Anthony (1998): Method in Translation History. Manchester: St. Jerome Publishing.

Souza de Carvalho, Ricardo (2009): Do catalão ao portugués: João Cabral tradutor. Revista de Letras. 49(1 enero-junio de 2009):137-149. Consultado el 3 de diciembre de 2012, <http:// www.jstor.org/discover/10.2307/40284696? uid=3737664\&uid=2129\&uid=2\&uid=70\&uid= 4\&sid=21101116900677>.

Triadú, Joan (1948): Brasil i Catalunya. Ariel. 16(abril de 1948):40.

Woodsworth, Judith (1998): History of Translation. In: Mona BAKer, ed. Encyclopedia of Translation Studies. Londres/Nueva York: Routledge, 100-105. 


\section{ANEXO}

\section{Obras de Joan Brossa publicadas en Brasil}

- «6 poemas de Joan Brossa» y «Poema». Traducción y nota de Sérgio Alcides y Ronald Polito. Suplemento Literário de Minas Gerais. 23 (marzo de 1997):14-15 y 24.

- «Três poemas». Traducción de Sérgio Alcides y Ronald Polito. Inimigo Rumor. 2 (mayo-agosto de 1997):44-49.

- «8ito poemas». Traducción y presentación de Sérgio Alcides y Ronald Polito. Magma. 4 (1997):97-100.

- «Nove poemas». Traducción y presentación de Ronald Polito y Sérgio Alcides. O Percevejo. 6 (1998):137-142.

- Poemas civis. Traducción, notas y epílogo de Sérgio Alcides y Ronald Polito. Río de Janeiro: Sette Letras, 1998.

- «Dossié Joan Brossa, 1919-1998». Edición de João Bandeira; traducciones de João Bandeira, Noemi Jaffe, Sérgio Alcides y Ronald Polito; textos de João Bandeira, Andrés Sánchez Robayna, Wally Salomão, Haroldo de Campos y João Cabral de Melo Neto. Cult. Revista Brasileira de Literatura. 19 (febrero de 1999):37-55.

- «2 poemas visuales». Suplemento Literário de Minas Gerais. 62 (agosto de 2000):2-3.

- «Seis poemas». Traducción de Ronald Polito. Cacto. 1 (agosto de 2002):84-87.

- Dossier Joan Brossa. Traducción de Ronald Polito. Zine Qua Non. 5 (septiembre de 2002):2.

- Marcelo Terça-Nada. "Joan Brossa: pequeno panorama sobre sua vida e obra». Incluye 11 poemas visuales, poemas objeto e instalaciones. Revista Etcetera. 13 (2003).

- «Tres poemas». Traducción y nota de Andityas Soares de Moura. Suplemento Literário de Minas Gerais. 39 (1277, febrero de 2005):14-15.

- «Poemas do libro Passat festes (1995-2000)». Traducción de Adalberto Muller. Zunái. Revista de poesia \& debates (2005).

- André Vallias. «Oda a Marx». Versión en vídeo del poema visual del mismo nombre de Joan Brossa, sobre imágenes de Mário Peixoto y música de Hanns Eisler y Noel Rosa. Erratica (2005).

- Poesia vista. Traducción de Vanderley Mendonça; introducción de Glòria Bordons y Haroldo de Campos. São Paulo: Amauta Editorial y Ateliê Editorial, 2005.

- Sumário astral e outros poemes. Edición de Vanderley Mendonça y Glòria Bordons; prólogo y traducción al portugués de Ronald Polito; traducción al español de Pere Galceran-Uyà; texto de solapa de A. Montejo Navas. São Paulo: Amauta Editorial, 2006.

- Joan Brossa: desde Barcelona ao Novo Mundo. Traducciones de Sérgio Alcides; textos de G. Bordons, S. González Valenzuela, J. M. Bonet, J. Bandeira, J. Cabral de Melo, P. Oyarzun, A. Montejo Navas y F. Krahn. Río de Janeiro: Institut Ramon Lull y Fundació Joan Brossa, 2006.

- «Siete poemas». Traducción de Salomão Sousa. Portal de Poesía Ibero-Americana de Antonio Miranda, febrero de 2008 (http://www.antoniomiranda.com.br/Iberoamerica/espanha/ joan_brossa.html).

- «Oito poemas». Traducción de Ronald Polito. Centopeia. 5 de marzo de 2008.

- «Trecho de Set d’acció». Traducción de Antonio Cícero. Acontecimentos. Blog de Antonio Cicero, 14 de marzo de 2008.

- «Três poemas». Traducción de Ronald Polito. Sibila. Poesia e Cultura. 25 de abril de 2009.

- «Nove poemas». Traducciones de Ronald Polito, Sérgio Alcides y Victor da Rosa. Sopro. Panfleto político-cultural. 10 (mayo de 2009):4.

- 99 Poemas. Selección de Ronald Polito y Victor da Rosa; traducción y epílogo de Ronald Polito; prefacio de Victor da Rosa; coda de Adolfo Montejo Navas. São Paulo: Demônio Negro-Anna Blume, 2009.

- «12 poemas». Traducción de Ronald Polito. Zunái. Revista de poesia \& debates, 2010 (http:// www.revistazunai.com/). 
- «M’estava ajaçat...» / «Estava deitado...». Traducción de Antonio Cícero. Acontecimentos. Blog de Antonio Cícero, 25 de noviembre de 2010 (http://antoniocicero.blogspot.com.es/2010/11/ joan-brossa-mestava-ajacat-estava.html).

- «Dois poemas». Traducción de Adriandos de Lima. Rimaఓvia Poesia Nova, 3 de diciembre de 2010 (http://partidodoritmo.blogspot.com.br/search?updated-min=2010-01-01T00:00:0002:00\&updated-max=2011-01-01T00:00:00-02:00\&max-results $=50$ ).

- «Fim». Modo de Usar \& C,. 23 de abril de 2011 (http://revistamododeusar.blogspot.com. es/2011/04/joan-brossa-fim-performance-em.html).

- Escutem esse silencio. Traducción de Ronald Polito; prólogo de Victor da Rosa y Ronald Polito; epílogo de Guilherme Mansur. São Paulo: Lumme Editor, 2011. 